\title{
Cyclooxygenase-2 inhibitors for non-small-cell lung cancer: A phase II trial and literature review
}

\author{
HIROSHI YOKOUCHI ${ }^{1,2}$, KENYA KANAZAWA ${ }^{1}$, TAKASHI ISHIDA ${ }^{1}$, SATOSHI OIZUMI $^{2}$, \\ NAOFUMI SHINAGAWA ${ }^{2}$, NORIAKI SUKOH ${ }^{3}$, MASAO HARADA ${ }^{3}$, SHIGEAKI OGURA ${ }^{4}$, \\ MITSURU MUNAKATA ${ }^{1}$, HIROTOSHI DOSAKA-AKITA ${ }^{5}$, HIROSHI ISOBE ${ }^{6}$ and MASAHARU NISHIMURA ${ }^{2}$ \\ ${ }^{1}$ Department of Pulmonary Medicine, Fukushima Medical University, Fukushima 960-1295; \\ ${ }^{2}$ First Department of Medicine, Hokkaido University School of Medicine, Sapporo, Hokkaido 060-8648; \\ ${ }^{3}$ Department of Respiratory Medicine, National Hospital Organization Hokkaido Cancer Center, Sapporo, Hokkaido 003-0804; \\ ${ }^{4}$ Department of Respiratory Disease, Sapporo City General Hospital, Sapporo, Hokkaido 060-8604; \\ ${ }^{5}$ Department of Medical Oncology, Hokkaido University Graduate School of Medicine, Sapporo, Hokkaido 060-8648; \\ ${ }^{6}$ Department of Medical Oncology, KKR Sapporo Medical Center, Sapporo, Hokkaido 062-0931, Japan
}

Received April 16, 2014; Accepted May 13, 2014

DOI: $10.3892 / \mathrm{mco} .2014 .319$

\begin{abstract}
Several preclinical and clinical studies have demonstrated that cyclooxygenase-2 (COX-2) inhibitors are efficient for the treatment of non-small-cell lung cancer (NSCLC). However, two recent phase III clinical trials using COX-2 inhibitors in combination with platinum-based chemotherapy failed to demonstrate a survival benefit. Thus, validation and discussion regarding the usefulness of COX-2 inhibitors for patients with NSCLC are required. We conducted a prospective trial using $\mathrm{COX}-2$ inhibitors for the treatment of 50 NSCLC patients accrued between April, 2005 and July, 2006. Patients with untreated advanced NSCLC received oral meloxicam (150 mg daily), carboplatin (area under the curve $=5 \mathrm{mg} / \mathrm{ml} \mathrm{x} \mathrm{min} \mathrm{on} \mathrm{day} 1)$ and docetaxel $\left(60 \mathrm{mg} / \mathrm{m}^{2}\right.$ on day 1 ) every 3 weeks. The primary endpoint was response rate. The response and disease control rates were 36.0 and $76.0 \%$, respectively. The time-to-progression (TTP) and overall survival (OS) were 5.7 months [95\% confidence interval (CI): 4.6-6.7] and 13.7 months (95\% CI: 11.4-15.9), respectively. The 1-year survival ratio was $56.0 \%$. Grade 3 neuropathy was observed in only 1 patient. We performed tumor immunohistochemistry for COX-2 and p27 and investigated the correlation between their expression and clinical outcome. COX-2 expression in the tumor tended to correlate with a higher response rate $50.0 \%$ in the high- and $18.2 \%$ in the low-COX-2 group; $\mathrm{P}=0.092$ ). Based on our results and previous reports, various trial designs, such as the prospective use of COX-2 inhibitors
\end{abstract}

Correspondence to: Dr Hiroshi Yokouchi, Department of Pulmonary Medicine,Fukushima Medical University, 1 Hikariga-oka, Fukushima 960-1295, Japan

E-mail: yokouchi@fmu.ac.jp

Key words: non-small-cell lung cancer, cyclooxygenase-2, p27, carboplatin, docetaxel only for patients with COX-2-positive NSCLC, including the exploratory analysis of biomarkers associated with the COX-2 pathway, may be worth further consideration.

\section{Introduction}

Cyclooxygenase-2 (COX-2), the enzyme that converts arachidonic acid to prostaglandins (PGs), is expressed in a number of solid tumors and is associated with carcinogenesis, tumor proliferation, infiltration, metastasis, angiogenesis and resistance to anticancer drugs (1). In lung cancer cells, COX-2, which is particularly overexpressed in adenocarcinoma (2), is considered to be a negative predictor of survival in this subpopulation (3-7). Based on these reports, several clinical trials have been conducted for the potentiation of targeting COX-2 in lung cancer (8).

The cyclin-dependent kinase (Cdk) inhibitor p27 plays a critical role in cell cycle regulation from the G1 to the $\mathrm{S}$ phase by inhibiting Cdk4/6-cyclin D1 and Cdk2-cyclin E (9). Loss of p27 expression tends to be an unfavorable prognostic factor in patients with non-small-cell lung cancer (NSCLC) (10). Increased p27 expression is attributed to COX-2-independent mechanisms of G0/G1 arrest driven by COX-2 inhibitors (11). Thus, p27 expression may be another predictive factor of the response to COX-2 inhibitors.

Taxanes, such as paclitaxel and docetaxel, are microtubule-stabilizing agents that act by interfering with spindle microtubule dynamics, causing cell cycle arrest and apoptosis through activating a number of molecular pathways $(12,13)$. Taxanes are able to drive COX-2 expression, which is followed by increased prostaglandin $\mathrm{E}_{2}\left(\mathrm{PGE}_{2}\right)$ production (14); therefore, a complementary and additive or synergistic effect with COX-2 inhibitors may be expected. Moreover, the response to carboplatin plus docetaxel in Asian patients was reported to be statistically superior to that in Caucasian patients (15).

Based on the abovementioned findings, we projected a prospective phase II trial using carboplatin, docetaxel and a 

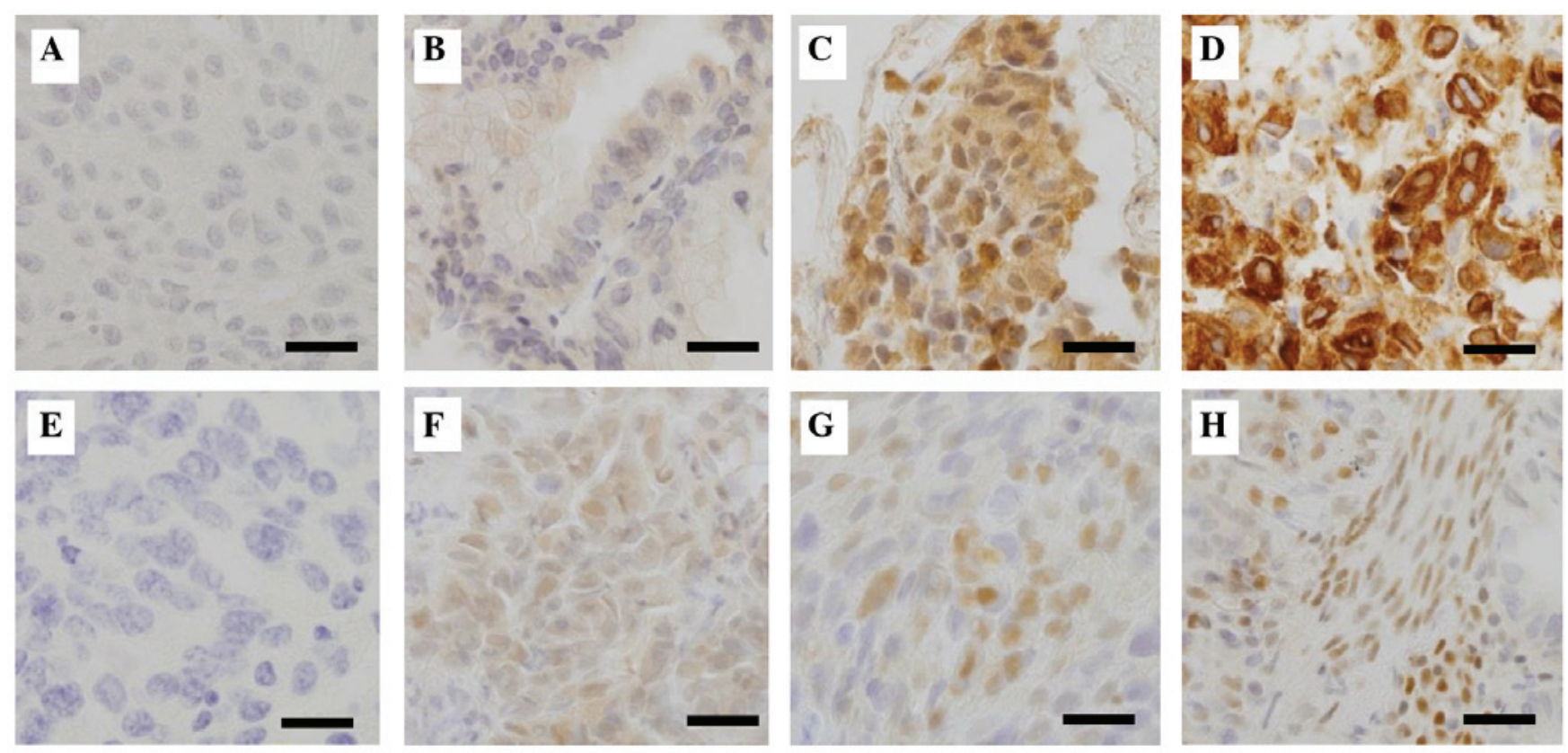

Figure 1. Representative immunohistochemical staining of (A-D) cyclooxygenase-2 and (E-H) p27 in lung cancer tissues obtained from the patients in this study. (A and E) 0, no expression; (B and F) 1+, weak expression; (C and G) 2+, moderate expression; and (D and H) 3+, strong expression. Scale bars, $250 \mu \mathrm{m}$.

selective COX-2 inhibitor for patients with advanced NSCLC. We also investigated the p27 and COX-2 expression levels in the tumors, so as to determine the correlation between these molecules and the clinical outcome of the combined treatment.

\section{Materials and methods}

Patient characteristics. The eligibility criteria included histologically or cytologically confirmed stage IIIB/IV NSCLC, a patient age of 20-75 years and a life expectancy of $>3$ months. The patients had measurable disease according to the Response Evaluation Criteria in Solid Tumors, version 1.0, had received no prior chemotherapy or radiotherapy for target lesions and had an Eastern Cooperative Oncology Group (ECOG) performance status (PS) of 0 or 1 . The required laboratory criteria were white blood cell (WBC) count $>4,000 / \mathrm{mm}^{3}$, neutrophil count $>2,000 / \mathrm{mm}^{3}$, platelet count $>100,000 / \mathrm{mm}^{3}$, hemoglobin $>9.0 \mathrm{~g} / \mathrm{dl}$, aspartate aminotransferase (AST) or alanine aminotransferase (ALT) $<1.5$-fold of the upper limit of the normal range (ULN), total bilirubin $<1.5 \mathrm{mg} / \mathrm{dl}$ and creatinine clearance $(\mathrm{CCr})>50 \mathrm{ml} / \mathrm{min}$. The exclusion criteria were active infection or fibrosis on chest X-ray, significant cardiovascular disease, uncontrolled diabetes mellitus or hypertension, peripheral nervous disorders of grade $\geq 2$ according to the Common Terminology Criteria for Adverse Events (CTCAE), version 3.0, active secondary malignancy, central nervous system symptoms due to metastasis, uncontrolled pleural or pericardial effusion, history of severe drug hypersensitivity, recent or current use of non-steroidal anti-inflammatory drugs, pregnancy, or patients deemed inappropriate for the study by the participating physicians.

This study was performed in accordance with the Declaration of Helsinki and all the patients signed an informed consent prior to inclusion. The study protocol was approved by the Institutional Review Board of each participating institution.
Study design and treatment protocol. This was a single-arm prospective phase II study. The dose of carboplatin was determined using the Calvert formula with a target area under the curve (AUC) of $5 \mathrm{mg} / \mathrm{ml} \mathrm{x} \mathrm{min.} \mathrm{All} \mathrm{the} \mathrm{patients}$ received docetaxel $\left(60 \mathrm{mg} / \mathrm{m}^{2}\right)$ and carboplatin at an AUC of $5 \mathrm{mg} / \mathrm{ml} \mathrm{x}$ min on day 1 every 3 weeks. Oral meloxicam at a dose of $10 \mathrm{mg}$ daily was administered on days $1-21$. We investigated p27 and COX-2 expression levels in tumors by immunohistochemistry (IHC). Dose reduction was permitted in the case of grade 4 neutropenia for 3 consecutive days, febrile neutropenia, or patient-physician's decision. The next course of chemotherapy was postponed in case of bone marrow suppression (WBC count $<3,000 / \mathrm{mm}^{3}$, or neutrophil count $<1,500 / \mathrm{mm}^{3}$, or platelet count $<100,000 / \mathrm{mm}^{3}$ ), non-hematological events (total bilirubin $>1.5 \mathrm{mg} / \mathrm{dl}$, AST $>1.5 \times$ ULN, ALT $>1.5 \times$ ULN, or $\mathrm{CCr}<50 \mathrm{ml} / \mathrm{min}$ ) and any non-hematological grade 2 adverse events. The clinical, hematological and biochemical status was assessed on days 1,8 and 15 in all the courses. Chest radiographs and computed tomography were performed at least once per month. The toxicities were graded using CTCAE, version 3.0.

IHC. IHC was centrally performed at SRL, Inc. (Tokyo, Japan). First, 5- $\mu \mathrm{m}$ sections of the specimens were deparaffinized and hydrated. For antigen retrieval, the slides were microwaved 4 times in $1 \mathrm{mM}$ EDTA (pH 8.0) for $5 \mathrm{~min}$. For COX-2 detection, staining was performed on an automated immunostainer (Ventana NX system; Ventana Medical Systems, Inc., Tucson, AZ, USA). The Endogenous Biotin Blocking kit (Ventana) was used to reduce non-specific staining caused by endogenous biotin present in the tissues. Subsequently, primary antibody (C295; anti-human COX-2 rabbit IgG polyclonal antibody; IBL Co., Ltd., Nagoya, Japan) diluted 1:25 was used for $30 \mathrm{~min}$ at $37^{\circ} \mathrm{C}$, followed by biotinylated goat anti-rabbit immunoglobulins (E0432; Dako, Glostrup, Denmark) diluted 1:500 and the 3-3'-diaminobenzidine tetrahydrochloride (DAB) kit (Ventana). 
The sections were then counterstained with hematoxylin for 1 min. For p27 detection, following antigen retrieval as described above, endogenous peroxidase activity was blocked by $3 \%$ hydrogen peroxidase in phosphate-buffered saline (PBS) for $10 \mathrm{~min}$. The sections were washed in water. After blocking non-specific binding with $10 \%$ porcine serum in PBS for $10 \mathrm{~min}$, the sections were incubated with the primary antibody (F-8; anti-human p27 mouse IgG1 monoclonal antibody; Santa Cruz, Dallas, TX, USA) diluted 1:50 in a humid chamber at $4^{\circ} \mathrm{C}$ overnight. After washing with water, the sections were incubated with biotinylated rabbit anti-mouse immunoglobulins (E0464) (dilution, 1:500; Dako, Glostrup, Denmark) for $30 \mathrm{~min}$ at room temperature, washed in water again and then incubated with peroxidase-conjugated streptavidin (dilution, 1:500; Dako) for $30 \mathrm{~min}$ at room temperature. Following an additional wash in water, DAB was applied for $5 \mathrm{~min}$ and the sections were counterstained with hematoxylin for $1 \mathrm{~min}$.

All the slides were reviewed by two pulmonary oncologists who were blinded to the clinical information. The slides were scored in a method similar to that previously described (weighted index) $(16,17)$. Five random fields per slide at x200 magnification were evaluated to determine the ratio (\%) of stained cells and intensity. The estimated ratios of stained cells were between $0 \%(0)$ and $100 \%(1.0)$, with intervals at a $10 \%$ grade. Intensity was scored using a numerical scale $(0$, no expression; $1+$, weak expression; $2+$, moderate expression; and $3+$, strong expression, Fig. 1). The index (0-3) was calculated as $\%$ positive staining $\mathrm{x}$ intensity score.

Statistical analysis. The primary endpoint was overall response rate (ORR), defined as the proportion of patients whose best response was either complete or partial response (PR) in the intent-to-treat (ITT) analysis. Assuming that an ORR of $45.0 \%$ in eligible patients would indicate potential usefulness, whereas an ORR of $25.0 \%$ would be the lower limit of interest, with $\alpha=0.05$ and $\beta=0.20,45$ patients were required. The secondary endpoints were safety, time-to-progression (TTP), overall survival (OS), OS rate at 1 year and correlation between OS and the expression level of COX-2 and p27. The TTP and OS were estimated using the Kaplan-Meier method. Log-rank tests were used to evaluate the differences in TTP and OS between patients with positive and those with negative COX-2 and p27 expression, as determined by IHC. The association between the protein levels of COX-2 and p27 was evaluated using the Pearson's product-moment correlation coefficient. The correlation between COX-2 and p27 expression and the response rate was evaluated using the Fisher's exact probability test. The statistical analysis was performed using SPSS software, version 20 (IBM Corporation, Armonk, NY, USA). P $\leq 0.05$ was considered to indicate statistically significant differences.

\section{Results}

Patient characteristics. Between April, 2005 and July, 2006, 50 NSCLC patients were enrolled from 5 institutions. The patients' baseline characteristics are summarized in Table I. The median age was 65 years (range, $44-78$ years), 17 patients were female and 24 had an ECOG PS of 1. One patient did not undergo treatment, due to disease progression after registration. The median number of treatment courses was 3 (range, 0-6).
Table I. Patient characteristics.

\begin{tabular}{|c|c|c|}
\hline \multirow[b]{2}{*}{ Characteristics } & \multicolumn{2}{|c|}{ Patients $(n=50)$} \\
\hline & No. & $\%$ \\
\hline Age, years [median (range)] & $65(44-78)$ & \\
\hline \multicolumn{3}{|l|}{ Gender } \\
\hline Female & 17 & 34.0 \\
\hline Male & 33 & 66.0 \\
\hline \multicolumn{3}{|l|}{ ECOG PS } \\
\hline 0 & 24 & 48.0 \\
\hline 1 & 26 & 52.0 \\
\hline \multicolumn{3}{|l|}{ Histology } \\
\hline Adenocarcinoma & 29 & 58.0 \\
\hline Squamous cell carcinoma & 18 & 36.0 \\
\hline Large-cell carcinoma & 2 & 4.0 \\
\hline Adenosquamous cell carcinoma & 1 & 2.0 \\
\hline \multicolumn{3}{|l|}{ Clinical stage (TNM, version 6) } \\
\hline IIIA & 1 & 2.0 \\
\hline IIIB & 15 & 30.0 \\
\hline IV & 32 & 64.0 \\
\hline Postoperative recurrence & 2 & 4.0 \\
\hline \multicolumn{3}{|l|}{ Courses of chemotherapy } \\
\hline 0 & 1 & 2.0 \\
\hline 1 & 5 & 10.0 \\
\hline 2 & 11 & 22.0 \\
\hline 3 & 9 & 18.0 \\
\hline 4 & 19 & 38.0 \\
\hline 5 & 3 & 6.0 \\
\hline 6 & 2 & 4.0 \\
\hline
\end{tabular}

ECOG PS, Eastern Cooperative Oncology Group performance status; TNM, tumor-node-metastasis.

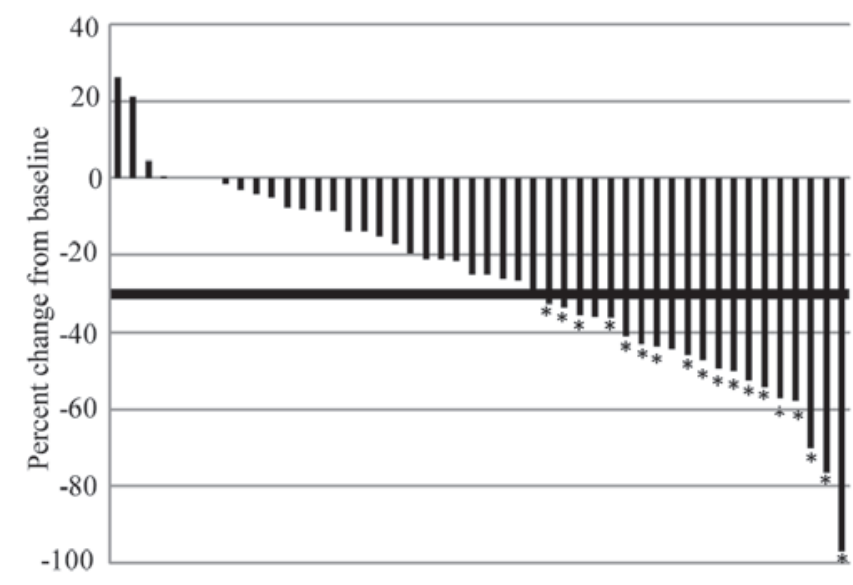

Figure 2. Waterfall plot for the extent of tumor shrinkage. The asterisks represent patients exhibiting a partial response.

Efficacy. A total of 49 patients were evaluable for response to treatment. The majority of the patients achieved tumor shrinkage (Fig. 2). According to the ITT analysis, the ORR 
Table II. Objective response (RECIST, version 1.0).

\begin{tabular}{lcr}
\hline Type of response & No. & $\%$ \\
\hline Number of patients evaluated & 50 & 100.0 \\
Complete response & 0 & 0.0 \\
Partial response & 18 & 36.0 \\
Stable disease & 20 & 40.0 \\
Progressive disease & 9 & 18.0 \\
Not evaluable & 3 & 6.0 \\
Response rate $(95 \% \mathrm{CI})$ & $36.0(24.1-49.9)$ \\
Disease control rate $(95 \% \mathrm{CI})$ & $76.0(62.5-85.8)$ \\
\hline
\end{tabular}

RECIST, Response Evaluation Criteria in Solid Tumors; CI, confidence interval.

was 36.0 (95\% CI: 24.1-49.9) and the disease control rate (DCR) was 76.0 (95\% CI: 62.5-85.8) (Table II). The median follow-up time was 12.9 months (range, 2.1-26.2 months). The TTP and OS were 5.7 months (95\% CI: 4.6-6.7) and 13.7 months (95\% CI: 11.4-15.9), respectively (Fig. 3). The OS rate at 1 year was $56.0 \%$.

Safety. The incidence of treatment-related adverse events is presented in Table III. The grade 3/4 hematological adverse events were leukopenia $(58.0 \%)$, neutropenia $(80.0 \%)$, anemia $(16.0 \%)$, thrombocytopenia $(4.0 \%)$ and febrile neutropenia $(8.0 \%)$. The grade $3 / 4$ non-hematological toxicities were anorexia (12.0\%), nausea/vomiting (8.0\%), diarrhea $(4.0 \%)$, fever $(4.0 \%)$, alopecia (2.0\%), neuropathy (2.0\%) and myopathy $(2.0 \%)$. One patient $(2.0 \%)$ had grade 3 angina pectoris: the patient experienced chest pain on day 3 during the first course of the treatment, which was relieved by immediate infusion of heparin and coronary vasodilator for 6 days; however, the patient's treatment was terminated. Another patient $(2.0 \%)$ suffered from febrile neutropenia and pneumonia followed by septic shock, requiring treatment with antibiotics and catecholamines on day 12 and developed deep vein thrombosis (DVT) in the left leg on day 26 during the second course of the treatment. The DVT was controlled using heparin followed by warfarin; however, the treatment protocol was discontinued.

Association between expression of 27 and COX-2 and clinical outcome. Tissue samples were obtained from $34(68.0 \%)$ of the 50 patients. Of the 34 samples, 32 were considered adequate for IHC. Of the 32 patients, 2 were not evaluable and one did not undergo treatment after registration. The expression of COX-2 and p27 was tabulated with clinical outcome and cut-off points were established by visual inspection of the data. We did not identify a correlation between the weighted index of COX-2 and that of p27. There was a trend of correlation between the level of COX-2 expression and ORR (50.0\% in the high- and 18.2\% in the low-COX-2 group; $\mathrm{P}=0.092$ ) when the cut-off value of the index was 0.2 (Table IV). The level of p27 expression was not associated with ORR $(54.5 \%$ in the high- and $27.8 \%$ in the low-p27 score group; $\mathrm{P}=0.24)$. The TTP and OS of the patients with positive and negative COX-2 expression were estimated by the Kaplan-Meier method; however there was no significant
Table III. Adverse events (CTCAE, version 3.0).

\begin{tabular}{lrrr}
\hline & \multicolumn{3}{c}{ Grade } \\
\cline { 2 - 4 } Adverse events & $1-2(\%)$ & $3(\%)$ & $4(\%)$ \\
\hline Leukopenia & 26.0 & 50.0 & 8.0 \\
Neutropenia & 6.0 & 14.0 & 66.0 \\
Anemia & 62.0 & 10.0 & 6.0 \\
Thrombocytopenia & 30.0 & 4.0 & 0.0 \\
Febrile neutropenia & 0.0 & 6.0 & 2.0 \\
Anorexia & 55.0 & 12.0 & 0.0 \\
Nausea/vomiting & 48.0 & 8.0 & 0.0 \\
Diarrhea & 18.0 & 4.0 & 0.0 \\
Fever & 28.0 & 4.0 & 0.0 \\
Alopecia & 44.0 & 2.0 & 0.0 \\
Neuropathy & 10.0 & 2.0 & 0.0 \\
Myopathy & 0.0 & 2.0 & 0.0 \\
Angina pectoris & 0.0 & 2.0 & 0.0 \\
Aphtha & 16.0 & 0.0 & 0.0 \\
Skin rash & 2.0 & 0.0 & 0.0 \\
Arthralgia & 2.0 & 0.0 & 0.0 \\
Thrombosis & 2.0 & 0.0 & 0.0 \\
\hline & & & \\
\hline
\end{tabular}

CTCAE, Common Terminology Criteria for Adverse Events.

Table IV. Correlation between COX-2 expression and response.

\begin{tabular}{lccc}
\hline COX-2 IHC index & PR & SD+PD & Total \\
\hline High & 9 & 9 & 18 \\
Low & 2 & 9 & 11 \\
Total & 11 & 18 & 29 \\
\hline
\end{tabular}

COX-2, cyclooxygenase-2; PR, partial response; SD, stable disease; $\mathrm{PD}$, progressive disease; IHC, immunohistochemistry.

difference between the two groups (TTP: 6.0 vs. 4.9 months, $\mathrm{P}=0.357$; and $\mathrm{OS}$ : 14.9 vs. 13.9 months; $\mathrm{P}=0.372$, respectively). There was also no significant difference in either TTP or OS between patients whose tumors were positive and those whose tumors were negative for p27 (TTP: 6.0 vs. 5.1 months, $\mathrm{P}=0.613$; and $\mathrm{OS}$ : 14.9 vs. 13.4 months, $\mathrm{P}=0.438$, respectively).

\section{Discussion}

In this trial, we investigated the effectiveness and toxicity of COX-2 inhibitors administered with carboplatin plus docetaxel in Japanese NSCLC patients and the association between tumor COX-2 and p27 expression and clinical outcome. There was a trend of correlation between the level of COX-2 expression and ORR. We first attempted to determine how p27 expression, which involves COX-2-independent mechanisms of G0/G1 arrest driven by COX-2 inhibitors, affects patient survival. However, the results revealed no statistical correlation. The 
Table V. Previous phase II-III studies of platinum doublet and COX-2 inhibitor in NSCLC.

\begin{tabular}{|c|c|c|c|c|c|c|c|c|}
\hline Design & Author (year) & $\begin{array}{l}\text { No. of } \\
\text { patients }\end{array}$ & $\begin{array}{l}\text { COX-2 } \\
\text { inhibitor }\end{array}$ & Chemotherapy & $\begin{array}{l}\text { Response } \\
\text { rate }(\%)\end{array}$ & $\begin{array}{c}\text { Median PFS } \\
\text { (months) }\end{array}$ & $\begin{array}{c}\text { Median OS } \\
\text { (months) }\end{array}$ & (Refs.) \\
\hline \multirow[t]{4}{*}{ Phase II } & Edelman et al (2008) & 45 & Celecoxib & CBDCA+GEM & NA & $4.3^{\mathrm{a}}$ & 11.8 & (23) \\
\hline & Wang et al (2008) & 44 & Celecoxib & $\begin{array}{l}\text { CDDP+GEM } \\
\text { CDDP+VNR } \\
\text { CDDP+DOC }\end{array}$ & 45.0 & 6.0 & 18.0 & (24) \\
\hline & Suzuki et al (2009) & 44 & Meloxicam & $\mathrm{CBDCA}+\mathrm{PTX}$ & 43.0 & $5.4^{\mathrm{b}}$ & 15.9 & $(35)$ \\
\hline & This study & 50 & Meloxicam & $\mathrm{CBDCA}+\mathrm{DOC}$ & 36.0 & $5.7^{\mathrm{b}}$ & 13.7 & \\
\hline \multirow[t]{10}{*}{ Phase III } & Groen et al (2011) & 281 & Celecoxib & $\mathrm{CBDCA}+\mathrm{DOC}$ & 38.0 & 4.5 & 8.2 & $(21)$ \\
\hline & & 280 & Placebo & & 30.0 & 4.0 & 8.2 & \\
\hline & HR & & & & & 0.8 & 0.9 & \\
\hline & $95 \% \mathrm{CI}$ & & & & & $0.6-1.1$ & $0.6-1.2$ & \\
\hline & P-value & & & & & 0.25 & 0.32 & \\
\hline & Koch et al (2011) & 158 & Celecoxib & 3rd generation & 36.0 & 6.1 & 8.9 & $(22)$ \\
\hline & & 158 & Placebo & Drug + platinum & 31.0 & 6.5 & 7.9 & \\
\hline & HR & & & & & 1.01 & 1.0 & \\
\hline & $95 \% \mathrm{CI}$ & & & & & $0.77-1.33$ & $0.79-1.26$ & \\
\hline & $\mathrm{P}$-value & & & & & 0.94 & 0.97 & \\
\hline
\end{tabular}

${ }^{a}$ Failure-free survival. ${ }^{b}$ Time-to-progression. COX-2, cyclooxygenase-2; NSCLC, non-small-cell lung cancer; PFS, progression-free survival; OS, overall survival; CBDCA, carboplatin; GEM, gemcitabine; NA, not available; CDDP, cisplatin; VNR, vinorelbine; DOC, docetaxel; PTX, paclitaxel; HR, hazard ratio to placebo; CI, confidence interval.
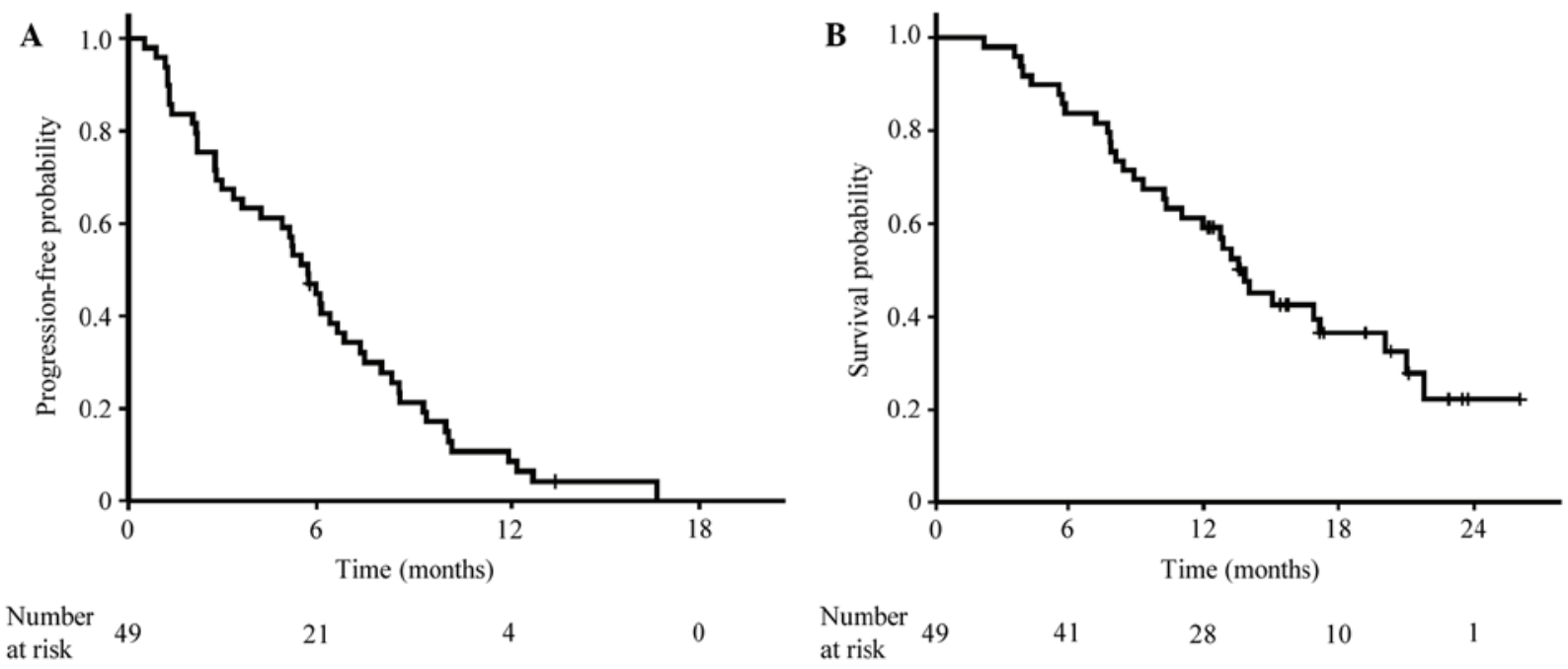

Figure 3. Survival outcomes after treatment. Kaplan-Meier estimates of (A) time-to-progression and (B) overall survival. Vertical bars, censored cases at the data cut-off point.

overall treatment efficacy was favorable, but was not enhanced by COX-2 inhibitors in terms of tumor response $(36.0 \%)$, OS (13.7 months) and 1-year survival ratio (56.0\%). Previous phase II-III trials of docetaxel and carboplatin without COX-2 inhibitors for advanced NSCLC demonstrated that the ORR, OS and 1-year survival rate were 16.0-55.0\%, 9.0-13.9 months and $44.0-58.0 \%$, respectively $(15,18-20)$. The incidence of adverse events, such as grade $3 / 4$ neutropenia $(80.0 \%)$ and febrile neutropenia $(8.0 \%)$, was similar to those previously reported (51.1-79.0 and 3.3-26.0\%, respectively). The frequen- cies of grade $3 / 4$ myopathy $(2.0 \%)$ and arthralgia $(0.0 \%)$ were comparable to or lower compared to those reported by several phase II trials using carboplatin plus docetaxel without a COX-2 inhibitor (3.0-4.0 and 3.0\%, respectively) $(15,18)$.

Two recent phase III trials (Table V) $(21,22)$ that used a design identical or similar to that of our study, failed to demonstrate any survival benefit with the addition of a COX-2 inhibitor to chemotherapy in patients with advanced NSCLC. Groen et al (21) demonstrated no statistical difference regarding survival between NSCLC patients with tumors 
positive and those with tumors negative for COX-2 expression, as determined by IHC.

To elucidate whether COX-2 inhibitors are beneficial for NSCLC patients, we must consider several aspects of COX-2-based strategy based on previous studies (Table V) and reports.

First, there have been no prospective phase III trials with the design of a COX-2 inhibitor or placebo used only in COX-2-positive patients with NSCLC. Groen et al (21) investigated the association between COX-2 positivity and progression-free survival (PFS) and OS as a subgroup analysis. A phase II trial (23) demonstrated that prospectively defined subset analysis indicated a survival advantage with a COX-2 inhibitor and chemotherapy in patients with moderate-to-high COX-2 expression. Another group conducted a phase II trial using COX-2 inhibitors combined with platinum-based chemotherapy in 44 previously untreated patients with COX-2-positive advanced NSCLC confirmed by IHC; that study reported promising results, with a median PFS and OS of 6 and 18 months, respectively (24).

Another reason supporting that we should focus on only COX-2-positive patients is the possibility of negative pharmacological effects of COX-2 inhibitors on patients with COX-2-negative tumors. Our results and those of a previous phase II trial (23) suggested that patients who do not express COX-2 may exhibit worse outcomes when treated with COX-2 inhibitors. The inhibition of COX-2 reportedly results in an imbalance between anti- and prothrombotic factors, with a predominance of thromboxane (TX) $\mathrm{A}_{2}$ at the expense of prostacyclin, which may trigger a series of cardiovascular complications (25). TXA $-\mathrm{TXA}_{2}$ receptor signaling facilitates tumor colonization through interaction of tumor cells with platelets and endothelial cells in the tumor microenvironment (26). TXA 2 is also known to promote tumor metastasis (27). Therefore, it is hypothesized that, by inhibiting COX-2, the COX-1 pathway may become dominant in normal cells, thereby assisting tumor growth in COX-2-negative cells. Other investigators reported that celecoxib treatment induced epithelial-to-mesenchymal transition, which promoted cell invasion and rendered cells resistant to chemotherapy (28). These negative effects may obscure the positive effects in COX-2-expressing patients.

Second, we have not fully pursued the subpopulation benefits for a COX-2 inhibitor on both the clinical and molecular basis. Kozak et al (29) found that markedly elevated urinary levels of the major $\mathrm{PGE}_{2}$ metabolite, which is a downstream signaling molecule of COX-2, were observed in patients with digital clubbing. Patients with high urinary levels of $\mathrm{PGE}_{2}$ may benefit from COX-2 inhibitors. Another group demonstrated that low pretreatment plasma levels of vascular endothelial growth factor are predictive of a positive effect of celecoxib on survival (30).

The molecular analysis-based selection of therapeutic agents for patients with advanced lung cancer is associated with significant benefits. The identification of epidermal growth factor receptor gene mutations (31) and the anaplastic lymphoma kinase fusion gene (32) contributed to predicting susceptibility to drugs such as gefitinib/erlotinib or crizotinib. The examination of the genetic background of a tumor may be crucial for identifying patients who may benefit from
COX-2 inhibitors. Although the genes of the COX pathway are rarely mutated in cancer cells (33), epigenetic alterations, such as DNA methylation, are recurrent events associated with longer recurrence times and improved OS in gastric cancer patients (34). Further investigation is required to determine the association of the genetic and epigenetic deregulation of the COX pathway with clinical outcome in lung cancer.

As shown in Table V, the OS in Asian patients with NSCLC appears to be longer compared to that in non-Asian patients (21-24,35). Pharmacoethnic differences in the response of cancer patients to certain drugs was recently reported (36). However, the diversity of the metabolic action of COX-2 inhibitors among different ethnicities has yet to be elucidated. Thus, identifying such differences may help achieve a better understanding of the molecular mechanism(s) underlying the response to COX-2 inhibitors.

In conclusion, although administered to only 'unselected' patients in a randomized phase III trial that yielded negative results, COX-2 inhibitors may be worth further consideration for the treatment of NSCLC patients.

\section{Acknowledgements}

The authors would like to thank Dr Koichi Yamazaki (deceased), former Associate Professor in the First Department of Medicine, Hokkaido University School of Medicine, for his support of this study.

\section{References}

1. Castelao JE, Bart RD III, DiPerna CA, Sievers EM and Bremner RM: Lung cancer and cyclooxygenase-2. Ann Thorac Surg 76: 1327-1335, 2003

2. Wolff H, Saukkonen K, Anttila S, Karjalainen A, Vainio H and Ristimaki A: Expression of cyclooxygenase-2 in human lung carcinoma. Cancer Res 58: 4997-5001, 1998.

3. Achiwa H, Yatabe Y, Hida T, et al: Prognostic significance of elevated cyclooxygenase 2 expression in primary, resected lung adenocarcinomas. Clin Cancer Res 5: 1001-1005, 1999.

4. Khuri FR, Wu H, Lee JJ, et al: Cyclooxygenase-2 overexpression is a marker of poor prognosis in stage I non-small cell lung cancer. Clin Cancer Res 7: 861-867, 2001.

5. Brabender J, Park J, Metzger R, et al: Prognostic significance of cyclooxygenase 2 mRNA expression in non-small cell lung cancer. Ann Surg 235: 440-443, 2002.

6. Jiang H, Wang $\mathrm{J}$ and Zhao W: Cox-2 in non-small cell lung cancer: a meta-analysis. Clin Chim Acta 419: 26-32, 2013.

7. Zhan P, Qian Q and Yu LK: Prognostic value of COX-2 expression in patients with non-small cell lung cancer: a systematic review and meta-analysis. J Thorac Dis 5: 40-47, 2013.

8. Brown JR and DuBois RN: Cyclooxygenase as a target in lung cancer. Clin Cancer Res 10: 4266s-4269s, 2004.

9. Katayose Y, Kim M, Rakkar AN, et al: Promoting apoptosis: a novel activity associated with the cyclin-dependent kinase inhibitor p27. Cancer Res 57: 5441-5445, 1997.

10. Hommura F, Dosaka-Akita H, Mishina T, et al: Prognostic significance of p27KIP1 protein and ki-67 growth fraction in non-small cell lung cancers. Clin Cancer Res 6: 4073-4081, 2000

11. Grosch S, Tegeder I, Niederberger E, Brautigam L and Geisslinger G: COX-2 independent induction of cell cycle arrest and apoptosis in colon cancer cells by the selective COX-2 inhibitor celecoxib. FASEB J 15: 2742-2744, 2001.

12. Gligorov J and Lotz JP: Preclinical pharmacology of the taxanes: implications of the differences. Oncologist 9 (Suppl 2): 3-8, 2004.

13. Haldar S, Basu A and Croce CM: $\mathrm{Bcl} 2$ is the guardian of microtubule integrity. Cancer Res 57: 229-233, 1997.

14. Subbaramaiah K, Marmo TP, Dixon DA and Dannenberg AJ: Regulation of cyclooxygenase-2 mRNA stability by taxanes: evidence for involvement of p38, MAPKAPK-2, and HuR. J Biol Chem 278: 37637-37647, 2003. 
15. Millward MJ, Boyer MJ, Lehnert M, et al: Docetaxel and carboplatin is an active regimen in advanced non-small-cell lung cancer: a phase II study in Caucasian and Asian patients. Ann Oncol 14: 449-454, 2003.

16. Zhang X, Hunt JL, Landsittel DP, et al: Correlation of protease-activated receptor-1 with differentiation markers in squamous cell carcinoma of the head and neck and its implication in lymph node metastasis. Clin Cancer Res 10: 8451-8459, 2004

17. Muller S, Su L, Tighiouart M, et al: Distinctive E-cadherin and epidermal growth factor receptor expression in metastatic and nonmetastatic head and neck squamous cell carcinoma: predictive and prognostic correlation. Cancer 113: 97-107, 2008.

18. Belani CP, Einzig A, Bonomi P, et al: Multicenter phase II trial of docetaxel and carboplatin in patients with stage IIIB and IV non-small-cell lung cancer. Ann Oncol 11: 673-678, 2000.

19. Jahanzeb M, Sarna G, Hirsch R, et al: Docetaxel and carboplatin as first-line therapy in advanced non-small cell lung carcinoma: a phase II study. Anticancer Res 24: 1239-1242, 2004.

20. Schuette W, Nagel S, von Weikersthal LF, et al: Randomized phase III trial of docetaxel plus carboplatin with or without levofloxacin prophylaxis in elderly patients with advanced non-small cell lung cancer: the APRONTA trial. J Thorac Oncol 6: 2090-2096, 2011.

21. Groen HJ, Sietsma H, Vincent A, et al: Randomized, placebo-controlled phase III study of docetaxel plus carboplatin with celecoxib and cyclooxygenase- 2 expression as a biomarker for patients with advanced non-small-cell lung cancer: the NVALT-4 study. J Clin Oncol 29: 4320-4326, 2011.

22. Koch A, Bergman B, Holmberg E, et al; Swedish Lung Cancer Study Group: Effect of celecoxib on survival in patients with advanced non-small cell lung cancer: a double blind randomised clinical phase III trial (CYCLUS study) by the Swedish Lung Cancer Study Group. Eur J Cancer 47: 1546-1555, 2011.

23. Edelman MJ, Watson D, Wang X, et al: Eicosanoid modulation in advanced lung cancer: cyclooxygenase- 2 expression is a positive predictive factor for celecoxib+chemotherapy - Cancer and Leukemia Group B Trial 30203. J Clin Oncol 26: 848-855, 2008.

24. Wang Z, Duan J, Guo Q, et al: A phase II clinical trial of celecoxib combined with platinum-based chemotherapy in the treatment of patients with advanced NSCLC as first-line treatment. Chin J Lung Cancer 11: 425-430, 2008 (In Chinese).
25. Mendes RT, Stanczyk CP, Sordi R, Otuki MF, dos Santos FA and Fernandes D: Selective inhibition of cyclooxygenase-2: risks and benefits. Rev Bras Reumatol 52: 767-782, 2012

26. Matsui $\mathrm{Y}$, Amano $\mathrm{H}$, Ito $\mathrm{Y}$, et al: Thromboxane $\mathrm{A}_{2}$ receptor signaling facilitates tumor colonization through P-selectin-mediated interaction of tumor cells with platelets and endothelial cells. Cancer Sci 103: 700-707, 2012.

27. Honn KV: Inhibition of tumor cell metastasis by modulation of the vascular prostacyclin/thromboxane A2 system. Clin Exp Metastasis 1: 103-114, 1983.

28. Wang ZL, Fan ZQ, Jiang HD and Qu JM: Selective Cox-2 inhibitor celecoxib induces epithelial-mesenchymal transition in human lung cancer cells via activating MEK-ERK signaling. Carcinogenesis 34: 638-646, 2013.

29. Kozak KR, Milne GL, Bentzen SM and Yock TI: Elevation of prostaglandin E2 in lung cancer patients with digital clubbing. J Thorac Oncol 7: 1877-1878, 2012.

30. Sorenson S, Fohlin H, Lindgren A, et al: Predictive role of plasma vascular endothelial growth factor for the effect of celecoxib in advanced non-small cell lung cancer treated with chemotherapy. Eur J Cancer 49: 115-120, 2013.

31. Lynch TJ, Bell DW, Sordella R, et al: Activating mutations in the epidermal growth factor receptor underlying responsiveness of non-small-cell lung cancer to gefitinib. N Engl J Med 350: 2129-2139, 2004.

32. Soda M, Choi YL, Enomoto M, et al: Identification of the transforming EML4-ALK fusion gene in non-small-cell lung cancer. Nature 448: 561-566, 2007.

33. Cebola I and Peinado MA: Epigenetic deregulation of the COX pathway in cancer. Prog Lipid Res 51: 301-313, 2012.

34. de Maat MF, van de Velde CJ, Umetani N, et al: Epigenetic silencing of cyclooxygenase-2 affects clinical outcome in gastric cancer. J Clin Oncol 25: 4887-4894, 2007.

35. Suzuki R, Yamamoto M, Saka H, et al: A phase II study of carboplatin and paclitacel with meloxicam. Lung Cancer 63: 72-76, 2009.

36. O'Donnell PH and Dolan ME: Cancer pharmacoethnicity: ethnic differences in susceptibility to the effects of chemotherapy. Clin Cancer Res 15: 4806-4814, 2009. 